\title{
Article \\ Environmental Enrichment Factors Associated with the Activity Level of Bottlenose Dolphins under Professional Care
}

\author{
Lisa K. Lauderdale ${ }^{1, * \mathbb{D}}$, Kenneth Alex Shorter ${ }^{2}$, Ding Zhang ${ }^{2} \mathbb{D}$, Joaquin Gabaldon ${ }^{3}$, Jill D. Mellen ${ }^{4}$, \\ Douglas A. Granger ${ }^{5}$, Michael T. Walsh ${ }^{6}$ and Lance J. Miller ${ }^{1}$
}

1 Conservation Science and Animal Welfare Research, Chicago Zoological Society-Brookfield Zoo, Brookfield, IL 60513, USA; lance.miller@czs.org

2 Department of Mechanical Engineering, University of Michigan, Ann Arbor, MI 48109, USA; kshorter@umich.edu (K.A.S.); zhding@umich.edu (D.Z.)

3 Robotics Institute, University of Michigan, Ann Arbor, MI 48109, USA; gabaldon@umich.edu

4 Biology Department, Portland State University, Portland, OR 97201, USA; jmellen@pdx.edu

5 Institute for Interdisciplinary Salivary Bioscience Research, University of California, Irvine, CA 92697, USA; dagrange@uci.edu

6 Department of Comparative, Diagnostic \& Population Medicine, University of Florida, Gainesville, FL 32611, USA; walshm@ufl.edu

* Correspondence: lisa.lauderdale@czs.org

check for updates

Citation: Lauderdale, L.K.; Shorter, K.A.; Zhang, D.; Gabaldon, J.; Mellen, J.D.; Granger, D.A.; Walsh, M.T.; Miller, L.J. Environmental Enrichment Factors Associated with the Activity Level of Bottlenose Dolphins under Professional Care. J. Zool. Bot. Gard. 2022, 3, 44-55. https://doi.org/10.3390/jzbg3010004

Academic Editor: Kris Descovich

Received: 12 October 2021

Accepted: 13 January 2022

Published: 21 January 2022

Publisher's Note: MDPI stays neutral with regard to jurisdictional claims in published maps and institutional affiliations.

Copyright: (c) 2022 by the authors. Licensee MDPI, Basel, Switzerland. This article is an open access article distributed under the terms and conditions of the Creative Commons Attribution (CC BY) license (https:// creativecommons.org/licenses/by/ $4.0 /)$.

\begin{abstract}
Environmental enrichment can be used to improve the welfare of dolphins in zoos and aquariums. Bottlenose dolphins under professional care are typically provided with a range of enrichment that has a variety of features and levels of complexity at various frequencies. In the present study, a subset of data from a larger study entitled "Towards understanding the welfare of cetaceans in zoos and aquariums" (colloquially called the Cetacean Welfare Study) was used to examine the relationship between activity level and enrichment buoyancy as well as enrichment provisioning schedules. Survey data were collected from accredited zoos and aquariums related to the types of enrichment provided to the dolphins and the frequency and duration they were supplied. Non-invasive bio-logging devices were used to record the dolphin kinematics one day per week over the course of two five-week data collection periods. Activity level related positively with the total duration of time non-stationary enrichment was provided. In addition, providing a larger number of enrichment types each between $26 \%$ and $50 \%$ of the days in a month (i.e., rotating many different types of enrichment across days on a moderate schedule) was positively related to activity level. Activity level was negatively related to the number of times sinking enrichment was provided. Understanding how the temporal schedule and features of various types of enrichment are related to activity levels will aid in developing progressively more effective enrichment programs.
\end{abstract}

Keywords: animal welfare; bottlenose dolphin; environmental enrichment; variable enrichment; overall dynamic body acceleration; zoo

\section{Introduction}

Environmental enrichment is a tool used by animal care staff to improve the welfare of cetaceans under professional care. Environmental enrichment is designed to provide opportunities for mental and physical stimulation and to encourage species-appropriate behavior through the addition of stimuli [1,2]. The goals of enrichment are to promote engagement, increase behavioral diversity, provide opportunities for behavioral choice, and give the animals control over their environment [3-6]. To achieve these objectives, environmental enrichment programs can incorporate enrichment types that function to stimulate cognitive, visual, auditory, feeding, and social systems [7].

Animals engaging in species-appropriate levels of activity is an important indicator of welfare [8]. While larger habitat sizes have been correlated with increased traveling distances for some terrestrial species [8], expanding the size of a habitat does not always result 
in increased habitat use or positive welfare. For example, chimpanzees (Pan troglodytes) transferred to a larger habitat did not locomote more often after the transfer [9]. Similarly, larger habitats were not associated with increased locomotion for African (Loxodonta africana) and Asian (Elephas maximus) elephants [10]. For these elephants, feeding diversity and an unpredictable feeding schedule were most influential in walking distance.

Enrichment is one tool that has been used to increase active behaviors and locomotion in several species in zoo environments. For example, food enrichment increased activity by $30 \%$ on days when it was provided to Asian elephants [11]. Hiding food inside of objects and throughout the enclosure of harbor seals (Phoca vitulina) increased the rate of species-appropriate foraging behaviors [12]. Food enrichment also increased the active behaviors of six species of felids [13]. Enrichment objects and problem-solving tasks are effective tools for increasing positive social play for chimpanzees (Pan troglodytes) and bottlenose dolphins (Tursiops truncatus) [14-16]. However, when floating ball and buoy enrichment is available to bottlenose dolphins, average swimming speeds can decline as they spend time swimming at a slower speed around the enrichment [17]. While many aspects of environmental enrichment have been investigated for bottlenose dolphins, very little has examined its relationship with activity level. For a detailed review of marine mammal enrichment in zoos and aquariums, see Brando et al. [18].

In addition to examining activity levels through monitoring active and locomotive behaviors, bio-logging tags can be used to record data about an individual animal's movement and orientation [19-22]. Bio-logging tags record fine-scale information related to an animal's movement, behavior, physiology, and/or environment [23]. In zoos, these types of wearable tags have been deployed to investigate activity budgets [11,22,24], recumbency [25,26], walking distances/locomotion [10,27,28], estrus [29], body orientation [24], and behavioral states [30]. Bio-logging devices are powerful tools for monitoring aspects of activity-related welfare as activity level is a contributor to and an indicator of health [31]. For example, low activity levels can be considered an indicator of poor welfare [32,33], while active behaviors can mitigate the risk of developing some illnesses [34-36]. For bottlenose dolphins under professional care, the frequency of receiving new enrichment on a monthly/weekly basis has been associated with increased activity level when compared to receiving new enrichment less often [37]. In addition, providing enrichment on a random schedule was associated with reduced activity level when compared to a predictable schedule.

Previous research suggests that enrichment can be used to improve animal welfare by increasing activity levels [10-13]. The relationships between ODBA and demographic, training, and environmental variables such as age, sex, training session duration, habitat type, and social management were explored in a prior publication [37]. The findings suggested that receiving enrichment on a random schedule was associated with lower ODBA values than receiving it on a predictable schedule, and higher ODBA values were associated with providing novel enrichment on a monthly/weekly schedule compared to a yearly/year+ schedule. Thus, the goal of the present study was to dive deeper into the relationships between ODBA and enrichment features. The present study explored more deeply how access to enrichment and the features of the enrichment are related to the activity levels of dolphins in accredited zoos and aquariums.

\section{Materials and Methods}

\subsection{Subjects and Facilities}

The data presented in the current study were collected as one component of a larger study entitled "Towards understanding the welfare of cetaceans in zoos and aquariums" (Cetacean Welfare Study). All zoos and aquariums accredited by the Alliance of Marine Mammal Parks and/or Aquariums or the Association of Zoos and Aquariums that housed common and Indo-Pacific bottlenose dolphins (Tursiops aduncus), beluga whales (Delphinapterus leucas), or Pacific white-sided dolphins (Lagenorhynchus obliquidens) in 2017 were contacted regarding participation in the Cetacean Welfare Study. Zoos and aquariums that 
agreed to participate were included in the study. Data were collected for two common bottlenose dolphins or Indo-Pacific bottlenose dolphins living in each of the participating habitats using a semi-random sampling design in order to create a balanced representation (i.e., age/sex) of dolphins under professional care at these locations. Bio-logging tag (MTags) data were collected from a total of 65 dolphins at 35 facilities. Participating facilities were in Bermuda $(n=1)$, Hong Kong $(n=1)$, Jamaica $(n=2)$, Mexico $(n=15)$, Singapore $(n=1)$, Spain $(n=1)$, and the United States $(n=14)$. Dolphin habitats included both professionally managed zoo/aquarium habitats and professionally managed ocean habitats. Professionally managed zoo/aquarium habitats were defined as fabricated habitats with or without exposure to weather patterns. Professionally managed ocean habitats were defined as cordoned-off sections of coastal ocean, bays, lagoons, or waterways. In the present manuscript, they will be collectively referred to as "habitats".

\subsection{Data Collection}

Data for the Cetacean Welfare Study were collected during two five-week data collection periods. The first data collection period was from July 2018 through November 2018, and the second period was from January 2019 through April 2019. The present study used a subset of data from the Cetacean Welfare Study, which included environmental enrichment data from a management survey (Section 2.3) and measures of physical activity obtained from MTags (Section 2.4). The management survey (English language) was sent to staff at participating facilities via an online link (Momentive Inc., San Mateo, CA, USA) in 2018. Six bottlenose dolphins that participated in the 2018 data collection period were unable to be retained for the 2019 data collection period, and six new bottlenose dolphins (from the respective habitat) were added to the study for the second data collection period. Surveys for the additional six individuals added to the 2019 data collection period were distributed in 2019. Upon submission, response reports were stored on a secure server and were de-identified for analysis. To collect bio-logging data, two bottlenose dolphin participants at each location wore the MTags on a Tuesday and Friday alternating schedule. The MTags were worn throughout the dolphin's normal daily activities once per week.

\subsection{Management Survey}

Staff from each of the participating zoos and aquariums completed a survey of management practices related to their two focal dolphins. Survey respondents were animal care and management staff who worked directly with the focal dolphins. Each focal dolphin's name was embedded in the questions to ensure that responses were specific to each observed dolphin. Experts in animal welfare, cetacean management, and veterinary medicine developed the survey questions. Questions were presented conditionally based on the previous response. The survey requested information regarding the dolphin's demographic information, the facilities' enrichment and training practices, and the habitat characteristics. Specifically, the enrichment section included questions about the types of enrichment available to the dolphins, the enrichment's features (i.e., floating or sinking), the number of days per month the focal dolphin had access to the enrichment, and the average duration of time that the dolphin had access to the enrichment (Supplementary Material). The options for types of enrichment included: above water and scuba play, balls/buoy, boomer/beach balls, bubble machines, changing conspecifics, dead fish, feeder balls/spools, foam rollers/bats/sticks, hula hoops, ice/gelatin, kayaking/Zorb balls, Legos/dive bricks, live fish, mats/sleds/icebergs, mirrors/television/movies, noodles, puzzle feeders, rub ropes/seaweed boas, tubs, underwater music/sounds, underwater window play, and water spray/brush boards.

\subsection{Bio-Logging Data}

MTag bio-logging devices were used to monitor activity levels. MTags were $150 \mathrm{~mm}$ long and $76 \mathrm{~mm}$ wide and were attached to the dolphins non-invasively approximately $20 \mathrm{~cm}$ behind the blowhole via four silicone suction cups. The silicone suction cups were 
specially designed to attach to the dolphins without impact to the skin. Focal dolphins were trained using positive reinforcement to wear the MTags prior to data collection. MTags could be easily removed by the animal care staff at any time. Similar biologging devices have been used extensively with wild dolphins and whales prior to application in this study. The MTag had a hydrodynamic profile to reduce drag imparted to the dolphin [38]. The MTag's electronics were based on the Loggerhead Instruments OpenTag3 platform (Loggerhead Instruments, Florida, USA) with the goal of designing a bio-logger for dolphins under professional care. The primary board of the OpenTag3 contains a 9-degree-of-freedom (DOF) inertial measurement unit (IMU; accelerometer, magnetometer, and gyroscope) and sensors to measure environmental pressure and temperature. IMU data were sampled at $50 \mathrm{~Hz}$ (i.e., samples per second), and all other sensor data were sampled at $5 \mathrm{~Hz}$. The board was encased in epoxy for waterproofing and mounted in a 3D-printed housing (stereolithography on a Formlabs Inc. (Somerville, MA, USA) Form $2^{\mathrm{TM}}$ printer).

\subsection{Enrichment Variables}

Features of enrichment that were potentially relevant to dolphin welfare were selected to examine their relationship with activity levels. The types and features of environmental enrichment used by the participating facilities are presented in Table 1. The buoyancy of each type of enrichment was classified as floating, sinking, or non-stationary. Nonstationary enrichment was defined as enrichment that either existed or could be moved manually or autonomously through various depths in the water column or above the surface. Enrichment was classified as either simple or complex based on its membership to four categories. Categories included: cognitive, food, sensory, and social enrichment. If an enrichment type was only a member of one category, it was considered to be simple enrichment. If an enrichment type was a member of multiple categories, it was considered to be complex enrichment.

Table 1. Classification of enrichment as simple or complex based on its categorization as cognitive, food, sensory, and/or social enrichment.

\begin{tabular}{|c|c|c|c|c|c|c|}
\hline Enrichment Type & Buoyancy & Class & Cognitive & Food & Sensory & Social \\
\hline Above water and scuba play & Non-stationary & Complex & $\checkmark$ & & $\checkmark$ & $\checkmark$ \\
\hline Balls and buoys & Floating, Sinking & Simple & & & $\checkmark$ & \\
\hline Boomer and beach balls & Floating, Sinking & Simple & & & $\checkmark$ & \\
\hline Bubble machines & Floating, Sinking & Simple & & & $\checkmark$ & \\
\hline Changing conspecifics & Non-stationary & Complex & $\checkmark$ & & $\checkmark$ & $\checkmark$ \\
\hline Dead fish & Floating, Sinking & Simple & & $\checkmark$ & & \\
\hline Feeder balls and spools & Floating, Sinking & Complex & & $\checkmark$ & $\checkmark$ & \\
\hline Foam rollers, bats, and sticks & Floating, Sinking & Simple & & & $\checkmark$ & \\
\hline Hula hoops & Floating, Sinking & Simple & & & $\checkmark$ & \\
\hline Ice and gelatin & Floating, Sinking & Simple & & $\checkmark$ & & \\
\hline Kayaking and Zorb balls & Non-stationary & Complex & & & $\checkmark$ & $\checkmark$ \\
\hline Legos and dive bricks & Floating, Sinking & Simple & & & $\checkmark$ & \\
\hline Live fish & Non-stationary & Complex & $\checkmark$ & $\checkmark$ & $\checkmark$ & \\
\hline Mats, sleds, and icebergs & Floating, Sinking & Simple & & & $\checkmark$ & \\
\hline Mirror, television, and movies & Floating, Sinking & Simple & & & $\checkmark$ & \\
\hline Noodles & Floating, Sinking & Simple & & & $\checkmark$ & \\
\hline Puzzle feeders & Floating, Sinking & Complex & $\checkmark$ & $\checkmark$ & $\checkmark$ & \\
\hline Rub ropes and seaweed boas & Floating, Sinking & Simple & & & $\checkmark$ & \\
\hline Tubs & Floating, Sinking & Simple & & & $\checkmark$ & \\
\hline Underwater music or sounds & Non-stationary & Simple & & & $\checkmark$ & \\
\hline Underwater window play & Non-stationary & Complex & $\checkmark$ & & $\checkmark$ & $\checkmark$ \\
\hline Water spray and brush boards & Floating, Sinking & Simple & & & $\checkmark$ & \\
\hline
\end{tabular}




\subsection{Data Analysis}

Descriptive statistics were calculated for the number of facilities that provided each category of floating, sinking, non-stationary, simple, and complex enrichment. Four variables were created: (1) The total number of times dolphins were provided with each enrichment category (i.e., cognitive, food, sensory, and social) was calculated by summing the number of times the enrichment in each category was provided; (2) The total duration that each category was provided was calculated by summing the duration that each type of enrichment within in that category was provided; (3) The percentage of the month associated with each type of enrichment was calculated by dividing the total number of times each type was provided by the number of days in the month; (4) The percent of the month that each enrichment type was provided was then categorized as having access $0-25 \%, 26-50 \%$, $51-75 \%$, or $76-100 \%$ of the month. The number of enrichment types in each category was summed to create the "Received \%" variables. As a simple example, dolphins could receive five types of enrichment in a month that included underwater window play six times, puzzle feeders ten times, hula hoops eight times, kayaking sixteen times, and rub ropes twenty-six times. This would result in one type of enrichment in the $0-25 \%$ variable, two types in the $26-50 \%$ variable, one type in the $51-75 \%$ variable, and one type in the $76-100 \%$ variable. The variable is representative of how much of the month the dolphins receive each different type of enrichment in the program, not the total number of days enrichment is provided.

MTag data were selected during times in which dolphins were outside of formal training sessions. The accelerometer, gyroscope, and magnetometer data on the MTags were used to estimate animal orientation (pitch, roll, and heading) [39]. Dynamic pitch was calculated by subtracting the static (low-pass filtered) pitch component from the original pitch data. A moving average filter with window size of $1.5 \mathrm{~s}$ was used for the low-pass filter. Specific acceleration was calculated by subtracting the gravitational component from the total accelerometer measurement, where the gravity direction was inferred using the estimated orientation of the animal. Overall dynamic body acceleration (ODBA) was calculated from the accelerometer data and was used to parameterize relative activity of the animal [40]. A moving average filter with a two-second window was used during the ODBA calculation. Analyses were conducted in MATLAB 9.7.0 using custom scripts.

Dolphins were included in the study if they had more than $240 \mathrm{~min}$ of MTag data recorded in either data collection period. If the first data collection period had more than $240 \mathrm{~min}$ of data, it was used in the analyses. If not, the second data collection period was used if there were more than $240 \mathrm{~min}$ of data. If neither data collection period had more than $240 \mathrm{~min}$, the dolphin was excluded from the analyses. Data from a single data collection period were used because dolphins without qualifying data in both periods would have to be excluded entirely during the construction of the generalized estimating equation (GEE) models. This data selection method maintained a large sample size and prioritized investigating variability across accredited facilities rather than within individuals. An independent $t$-test and a Chi-square test of significance were used to determine if the age and sex of the sample in the final data set were statistically different from the group of dolphins originally selected for participation.

Statistical models were examined using GEEs due to the non-normal distribution of the data. GEEs do not require data to be transformed, which preserves the interpretability of the results [41,42]. Facility ID was controlled for in all models and was treated as a random effect with an independent correlation structure. Initial models were built with univariate level predictors. Univariate models where $p<0.15$ were retained to develop multivariate models $[10,43]$. The multivariate model with the lowest quasi-likelihood under the independence model criterion (QIC) value and highest number of significant independent variables was selected as the final model. Analyses for the regression models were completed in SPSS 27 (IBM, New York, NY, USA). 


\section{Results}

The final dataset included MTag deployments from 60 bottlenose dolphins (male $n=35$, female $n=25$ ) at 31 facilities after excluding dolphins that did not meet the minimum criteria. The $\operatorname{sex}\left(\chi^{2}(1, n=125)=3.623, p=0.057\right)$ and age $(\mathrm{t}(123)=0.542, p=0.589)$ distributions of the group included in the analyses were not significantly different than those in the group prior to excluding dolphins that did not meet the inclusion criteria. The final group included 57 common bottlenose dolphins and three Indo-Pacific bottlenose dolphins that ranged in age from 3 to 44 years (mean $16.48 \pm 9.84 \mathrm{SD}$ ) at the start of data collection. In total, 35 participants lived in professionally managed zoo/aquarium habitats, and 25 participants lived in professionally managed ocean habitats. The mean maximum depth was $5.63 \mathrm{~m}$ in ocean habitats and $8.78 \mathrm{~m}$ for zoo/aquarium habitats. Lauderdale and colleagues [44] provided a detailed report of the characteristics of the habitats included in the present study. Data were collected for 1053.35 h (range: 255 to 2043 min per dolphin) during periods in which the dolphins were outside of formal training sessions. The mean ODBA value for all participants was $2.31 \pm 0.63 \mathrm{~m} / \mathrm{s}^{2}$. The number of habitats that provided each enrichment type is provided in Table 2.

Table 2. Number of habitats that provided each type of enrichment categorized as floating, sinking, and nonstationary.

\begin{tabular}{cccc}
\hline Enrichment Type & $\begin{array}{c}\text { Floating } \\
\text { Enrichment }\end{array}$ & $\begin{array}{c}\text { Sinking } \\
\text { Enrichment }\end{array}$ & $\begin{array}{c}\text { Non-Stationary } \\
\text { Enrichment }\end{array}$ \\
\hline Above water and scuba play & - & - & 24 \\
Balls and buoys & 31 & 8 & - \\
Boomer and beach balls & 16 & 4 & - \\
Bubble machines & 6 & 4 & 10 \\
Changing conspecifics & - & - & - \\
Dead fish & 5 & 5 & - \\
Feeder balls and spools & 11 & 1 & - \\
Foam rollers, bats, and sticks & 6 & 0 & - \\
Hula hoops & 23 & 10 & - \\
Ice and gelatin & 20 & 3 & - \\
Kayaking and Zorb balls & 20 & 0 & - \\
Legos and dive bricks & 2 & 1 & - \\
Live fish & - & - & - \\
Mats, sleds, and icebergs & 20 & 1 & - \\
Mirror, television, and movies & 7 & 7 & - \\
Noodles & 7 & 0 & - \\
Puzzle feeders & 5 & 1 & 6 \\
Rub ropes and seaweed boas & 15 & 11 & 9 \\
Tubs & 9 & 2 & - \\
Underwater music or sounds & - & - & - \\
Underwater window play & - & 1 & - \\
Water spray and brush boards & 22 & & -
\end{tabular}

Note: An individual enrichment program may have included both floating and sinking versions of an enrichment type.

The enrichment factors associated with ODBA were evaluated. Univariate correlations where $p<0.15$ were observed between ODBA and four variables (Table 3). Descriptive statistics for independent variables considered for multivariate analysis are presented in Table 4. 
Table 3. Univariate correlations between ODBA and independent variables.

\begin{tabular}{cccc}
\hline Independent Variable & $\boldsymbol{n}$ & Beta & $\boldsymbol{p}$ Value \\
\hline Floating Occurrences & 60 & 0.001 & 0.718 \\
Floating Duration & 60 & 0.000 & 0.811 \\
Sinking Occurrences & 60 & -0.006 & $0.050^{\wedge}$ \\
Sinking Duration & 60 & 0.000 & 0.618 \\
Non-stationary Occurrences & 60 & 0.003 & 0.546 \\
Non-stationary Duration & 60 & 0.001 & $0.003^{*}$ \\
Simple Occurrences & 60 & 0.000 & 0.830 \\
Simple Duration & 60 & 0.000 & 0.655 \\
Complex Occurrences & 60 & 0.006 & 0.198 \\
Complex Duration & 60 & 0.000 & 0.091 \\
Received 0-25\% & 60 & -0.023 & 0.154 \\
Received 26-50\% & 60 & 0.042 & $0.122^{\wedge}$ \\
Received 51-75\% & 60 & 0.036 & 0.466 \\
Received 76-100\% & 60 & -0.018 & 0.752 \\
\hline${ }^{\wedge} p$ value $<0.15$ used as threshold significant level for model building ${ }^{*} p$ value $<0.05$
\end{tabular}

${ }^{\wedge} p$ value $<0.15$ used as threshold significant level for model building ${ }^{*} p$ value $<0.05$.

Table 4. Descriptive statistics for independent variables included in the multivariable modeling process.

\begin{tabular}{ccccccc}
\hline Independent Variable & $\boldsymbol{n}$ & Mean & SD & Min & Max & Median \\
\hline Sinking Occurrences & 21 & 22.55 & 26.26 & 0.00 & 85.00 & 14.00 \\
Complex Duration & 26 & 333.71 & 567.14 & 0.00 & 2400.00 & 70.00 \\
Non-stationary Duration & 21 & 93.87 & 183.68 & 0.00 & 775.00 & 15.00 \\
Received 26-50\% & 25 & 2.68 & 2.749 & 0.00 & 10.00 & 2.00 \\
\hline
\end{tabular}

Note: $n=$ the number of zoos and aquariums that provided enrichment included in the respective variable.

The final multivariate model included the number of times sinking enrichment was provided, the total duration non-stationary enrichment was provided, and the number of the types of enrichment provided between $26 \%$ and $50 \%$ of the month (Table 5). Lower ODBA values were associated with the number of times sinking enrichment was provided $(\beta=-0.012, p<0.001)$. Higher ODBA values were associated with higher total durations of non-stationary enrichment $(\beta=0.001, p=0.001)$, and more types of enrichment being provided between $26 \%$ and $50 \%$ of the month $(\beta=0.046, p=0.038)$.

Table 5. Results for the final model examining ODBA.

\begin{tabular}{cccccc}
\hline Variable & \multirow{2}{*}{ Beta } & Std Error & $\begin{array}{c}\text { Lower 95\% } \\
\text { CI }\end{array}$ & $\begin{array}{c}\text { Upper 95\% } \\
\text { CI }\end{array}$ & $p$ Value \\
\hline (Intercept) & 2.319 & 0.090 & 2.143 & 2.495 & $<0.001$ \\
Sinking Occurrences & -0.012 & 0.003 & -0.018 & -0.007 & $<0.001$ \\
Non-stationary Duration & 0.001 & 0.000 & 0.001 & 0.002 & 0.001 \\
Received 26-50\% & 0.046 & 0.022 & 0.003 & 0.090 & 0.038 \\
\hline
\end{tabular}

\section{Discussion}

Activity levels (i.e., ODBA) were related to three features of environmental enrichment associated with both the duration and frequency of provisioning. Previous research suggests that environmental enrichment can be effective in increasing the habitat use and social play of bottlenose dolphins $[45,46]$. However, behavioral responses to different enrichment types and objects vary [47]. In the present study, dolphins receiving sinking enrichment more often had lower activity levels. Higher activity levels were related to dolphins receiving non-stationary enrichment for longer periods of time and receiving more types of enrichment between $26 \%$ and $50 \%$ of the month.

Dolphins under professional care occupy both the horizontal and vertical space within their habitat, which presents opportunities to implement enrichment that can be interacted 
with in a variety of locations. Many of the accredited zoos and aquariums participating in this study provided enrichment that extended throughout the vertical space available to dolphins. Using enrichment in a certain location can effectively increase use of that part of the habitat $[15,45]$. In the present study, the activity levels of dolphins were lower for those that were provided with sinking enrichment more often. One explanation for this result may be that the types of sinking enrichment used by the participating facilities promoted stationary interactions. For example, sinking hula hoops may have encouraged dolphins to interact with them in a fixed location due to their weight, whereas floating hula hoops may have facilitated the ability to swim with them more easily. Another potential contributor to the reduction in ODBA values were changes in swimming gait at deeper depths. During deeper dives, dolphins may employ a fluke-and-glide swimming gait, and spend more time gliding during ascent, both of which may have reduced the acceleration measured by the tags [22]. Therefore, potentially interacting with sinking enrichment at the bottom of a habitat may have resulted in small reductions in ODBA. However, the data suggested that the magnitude of this effect was quite small and that promoting the use of this part of the habitat may outweigh a very small reduction in activity.

While most of the enrichment provided by participating facilities was either floating or sinking, facilities also provided enrichment that was non-stationary (i.e., existed or could be moved manually or autonomously through various depths in the water column and above the surface). The effectiveness of these activities being used as enrichment has not previously been investigated for bottlenose dolphins. However, these types of enrichment have been effective in improving the welfare of other species under professional care. For example, providing opportunities to hunt live fish reduces stereotypic behavior in Sumatran tigers (Panthera tigris sumatrae) [48] and diversifies the behaviors of fishing cats (Prionailurus viverrinus) under professional care [49]. Activity levels of the dolphins in the present study were higher for those that had access to non-stationary enrichment for longer periods of time. While the results suggested that the magnitude of this effect was small, the positive relationship to ODBA levels may have been a result of the movement facilitated by these types of enrichment. Above water play, underwater window play, scuba play, changing conspecifics, and live fish may have encouraged the dolphins to increase their activities above levels seen during low-intensity swimming.

The predictability of positive events is thought to be an important factor affecting welfare [50]. Varying the temporal predictability of the presentation of enrichment and rewarding events can reduce the likelihood of habituation and maintain an animal's motivation to engage with the activity [51-53]. Previous research suggests that the engagement with enrichment remains highest when it is provided on a variable schedule at an intermediate level $[51,53,54]$. Presenting enrichment on an unpredictable or variable schedule can also result in decreased standing behaviors, decreased stereotypic behavior, increased behavioral range, and increased exploratory and foraging behaviors [49,54-58]. In the present study, dolphins who were provided with more types of enrichment between $26 \%$ and $50 \%$ of the days in a month had higher ODBA values. This suggested that, in general, providing each specific enrichment type between a quarter and half the month may be positively related to interactions with the enrichment, which may be associated with higher activity levels. Importantly, some dolphins have preferred enrichment objects that are resistant to habituation [47], and this should be considered when developing an enrichment schedule. Notably, this finding is not suggesting that enrichment should only be provided $26 \%$ to $50 \%$ of the month, but that providing more types of enrichment on this moderate schedule is related to higher activity levels. The enrichment programs in the present study generally included many enrichment types that can be provided simultaneously and rotationally [44]. For example, dolphins could receive three different enrichment types each day that are rotated from a program housing nine types. If provided equally, the dolphins would receive each enrichment type approximately 10 times per month but, importantly, would still be receiving multiple types of enrichment each day. Furthermore, each enrichment type (e.g., 
puzzle feeders) could include multiple objects or activities that could be rotated through as well.

For the present study, limitations include any behavioral changes that resulted from wearing the MTags. Although dolphins were trained and habituated to the MTags prior to data collection, it is possible that the focal dolphins modified their behavior due to its presence. In addition, the ODBA variable was not inclusive of all the time that the focal dolphin had access to enrichment, and behavioral observations were not collected to identify direct interactions with enrichment. Data were not limited to times in which dolphins had access to or were interacting with enrichment as enrichment has been associated with modified habitat use even when the enrichment is not directly available [45]. The findings were also limited by other factors that may influence ODBA including the dolphin's diet, training schedule, and social grouping. ODBA is an accurate proxy for activity level and generally proportional to the animal's activity but does have some limitations in an aquatic environment. Drag is reduced at deeper depths [59], which may result in lower ODBA values than those that would occur if the dolphin were swimming near the surface. In addition, less water resistance at and above the surface could result in higher measured acceleration for actions used while interacting with enrichment (e.g., tossing an object) than the same action at a deeper depth.

\section{Conclusions}

Both the frequency and duration that enrichment was provided to dolphins were related to activity levels. Higher ODBA values were associated with schedules that provided more enrichment types between $26 \%$ and $50 \%$ of the month. This suggested that rotating through daily enrichment types to present each different type of enrichment seven to 15 days of the month (excluding potentially preferred enrichment items) may be a beneficial frequency to promote higher activity levels. The number of times sinking enrichment was provided and the duration non-stationary enrichment was provided were also related to activity level. However, the magnitude of the effect was small, suggesting that they may not be a favorable method for increasing activity levels. Promoting welfare by prioritizing expanding habitat use with sinking enrichment may be more important than the small reductions in activity level, which may be due to changes in movement patterns at deeper depths or related to the stationary nature of sinking enrichment. Maintaining speciesappropriate activity levels is a meaningful factor to ensure positive welfare. Examining fine-scale changes in provisioning is a key next step. Understanding how the temporal presentation and features of various types of enrichment are related to activity levels will aid in developing progressively more effective enrichment programs for the future.

Supplementary Materials: The following supporting information can be downloaded at: https: / / www.mdpi.com/article/10.3390/jzbg3010004/s1. Supplementary S1: Cetacean Welfare Animal Enrichment Survey.

Author Contributions: Conceptualization, L.K.L., J.D.M., D.A.G., M.T.W. and L.J.M.; formal analysis, L.K.L. and L.J.M.; funding acquisition, J.D.M., D.A.G., M.T.W. and L.J.M.; methodology, L.K.L., J.D.M., D.A.G., M.T.W. and L.J.M.; project administration, L.K.L. and L.J.M.; validation, L.K.L., K.A.S., D.Z., J.G. and L.J.M.; writing—original draft, L.K.L.; writing—review and editing, L.K.L., K.A.S., D.Z., J.G., J.D.M., D.A.G., M.T.W. and L.J.M. All authors have read and agreed to the published version of the manuscript.

Funding: The work was funded by a National Leadership Grant (MG-30-17-0006-17) from the Institute of Museum and Library Services (www.imls.gov) to the Chicago Zoological Society. Additional financial support was provided to the Chicago Zoological Society for the present work by the Indianapolis Zoo, The Seas ${ }^{\circledR}$ Epcot $^{\circledR}$ Walt Disney World ${ }^{\circledR}$ Resort, Dolphin Island-Resorts World Sentosa, Texas State Aquarium, Loro Parque and Loro Parque Fundación, SeaWorld Busch Gardens Conservation Fund and the Chicago Zoological Society Women's Board. The Chicago Zoological Society provided financial support in the form of a salary for L.M., the University of California Irvine provided financial support for D.G.'s salary, and the University of Florida provided financial support for M.W.'s salary through Clearwater Marine Aquarium and Florida Fish and Wildlife 
Conservation Commission state funding. The specific roles of these authors are articulated in the "author contributions" section. The Indianapolis Zoo, The Seas ${ }^{\circledR}$ Epcot ${ }^{\circledR}$ Walt Disney World ${ }^{\circledR}$ Resort, Dolphin Island-Resorts World Sentosa, Texas State Aquarium, Loro Parque, and SeaWorld Parks also contributed to data collection as each of these facilities, as well as animals at the facilities, were involved in the study. The funders had no other role in study design, data collection and analysis, decision to publish, or preparation of the manuscript.

Institutional Review Board Statement: The study was approved by the Institutional Animal Care and Use Committee of the U.S. Navy Marine Mammal Program (protocol number 123-2017). In addition, this study was authorized by the management at each participating zoo and aquarium and, where applicable, was reviewed and approved by research committees. Institutional Review Board approval was not required for survey respondents because the questionnaire did not request personal information.

Informed Consent Statement: Informed consent was waived for survey respondents because the questionnaire did not request personal information.

Data Availability Statement: In order to protect the identification of the facilities and animals included in this study, findings require data access restrictions at the individual level. All relevant data are within the manuscript.

Acknowledgments: We would like to start by thanking Joy Mench and Melinda Conners for their significant efforts at the beginning of the project assisting with project design and review of methods. We would also like to thank Jocelyn Woods for all of her efforts in behavioral coding, data entry, and data processing. In addition, special thanks to the Alliance for Marine Mammal Parks and Aquariums and the Association of Zoos \& Aquariums for support throughout the duration of the project. We would also like to thank Sarah Breen-Bartecki and Bill Zeigler for their continued support and Rita Stacey and the Seven Seas staff for all of their original efforts in testing the MTags. We would like to acknowledge Cheryl Meehan, Joy Mench, Kathy Carlstead, Jennifer Hogan, and the additional co-authors of the Epidemiological Investigations of North American Zoo Elephant Welfare Collection for providing a framework for aspects of the present study. Finally, a sincere thank you to the people at each of the following facilities for making this project possible: Cabo Dolphins, Chicago Zoological Society-Brookfield Zoo, Delphinus Playa Mujeres, Delphinus Puerto Morelos, Delphinus Punta Cancún, Delphinus Riviera Maya, Delphinus Xcaret, Delphinus Xel-Há, Dolphin Adventure, Dolphin Discovery Akumal, Dolphin Discovery Cozumel, Dolphin Discovery Dreams, Dolphin Discovery Isla Mujeres, Dolphin Discovery Mahahual, Dolphin Discovery Maroma, Dolphin Discovery Moon Palace, Dolphin Discovery Ocho Rios, Dolphin Discovery Riviera Maya, Dolphin Island-Resorts World Sentosa, Dolphin Quest Hawaii, Dolphin Quest Oahu, Dolphin Quest Bermuda, Georgia Aquarium/Marineland Dolphin Adventure, Gulf World Marine Park, Gulfarium Marine Adventure Park, Indianapolis Zoo, Interactive Aquarium Cancun, John G. Shedd Aquarium, Lisbon Zoo Portugal, Loro Parque and Loro Parque Fundación, Mystic Aquarium, National Aquarium, Ocean Park Corporation, Sea Life Park Hawaii, Sea World Parks, Texas State Aquarium, The Mirage Dolphin Habitat and The Mirage Casino-Hotel LLC, The Seas ${ }^{\circledR}$ Epcot $^{\circledR}$ Walt Disney World ${ }^{\circledR}$ Resort, and the U.S. Navy Marine Mammal Program.

Conflicts of Interest: The authors have read the journal's policy, and the authors of the study have the following competing interests to declare: L.J.M. and L.K.L. are affiliated with the Chicago Zoological Society-Brookfield Zoo (an AZA and AMMPA accredited zoo), and Chicago Zoological Society provides a salary for L.J.M. Before the study, J.D.M. was previously affiliated with Disney's Animal Kingdom (an AZA accredited zoo). The Seas ${ }^{\circledR}$ Epcot $^{\circledR}$ Walt Disney World ${ }^{\circledR}$ Resort, Dolphin IslandResorts World Sentosa, and Loro Parque and Loro Parque Fundación provided funding to the Chicago Zoological Society for this study. This does not alter our adherence to editorial policies on sharing data and materials. There are no patents, products in development or marketed products associated with this research to declare.

\section{References}

1. Chamove, A.S. Environmental enrichment: A review. Anim. Technol. 1989, 40, 155-178.

2. White, B.C.; Houser, L.A.; Fuller, J.A.; Taylor, S.; Elliott, J.L. Activity-based exhibition of five mammalian species: Evaluation of behavioral changes. Zoo Biol. 2003, 22, 269-285. [CrossRef] 
3. Alligood, C.; Leighty, K. Putting the "E" in SPIDER: Evolving trends in the evaluation of environmental enrichment efficacy in zoological settings. Anim. Behav. Cogn. 2015, 2, 200-217. [CrossRef]

4. Kuczaj, S.A.; Lacinak, C.T.; Turner, T.N. Environmental Enrichment for Marine Mammals at Sea World. In Second Nature: Environmental Enrichment for Captive Animals; Shepherdson, D., Mellen, J., Hutchins, M., Eds.; Smithsonian Institution Press: Washington, DC, USA, 1998; pp. 314-328.

5. Mellen, J.; Sevenich MacPhee, M. Philosophy of environmental enrichment: Past, present, and future. Zoo Biol. 2001, 20, 211-226. [CrossRef]

6. Miller, L.J.; Pisacane, C.B.; Vicino, G.A. Relationship between behavioural diversity and faecal glucocorticoid metabolites: A case study with cheetahs (Acinonyx jubatus). Anim. Welf. 2016, 25, 325-329. [CrossRef]

7. Hoy, J.M.; Murray, P.J.; Tribe, A. Thirty years later: Enrichment practices for captive mammals. Zoo Biol. 2010, 29, 303-316. [CrossRef] [PubMed]

8. Breton, G.; Barrot, S. Influence of enclosure size on the distances covered and paced by captive tigers (Panthera tigris). Appl. Anim. Behav. Sci. 2014, 154, 66-75. [CrossRef]

9. Neal Webb, S.J.; Hau, J.; Schapiro, S.J. Captive chimpanzee (Pan troglodytes) behavior as a function of space per animal and enclosure type. Am. J. Primatol. 2018, 80, e22749. [CrossRef]

10. Holdgate, M.R.; Meehan, C.L.; Hogan, J.N.; Miller, L.J.; Soltis, J.; Andrews, J.; Shepherdson, D.J. Walking behavior of zoo elephants: Associations between GPS-measured daily walking distances and environmental factors, social factors, and welfare indicators. PLoS ONE 2016, 11, e0150331. [CrossRef]

11. Soulsby, K.S. Use of a Tri-Axial Accelerometer, Behavioral Observation, and GPS to Monitor the Activity of Female Asian Elephants in a Zoo. Master's Thesis, The University of Texas, Arlington, TX, USA, May 2012.

12. Grindrod, J.A.; Cleaver, J.A. Environmental enrichment reduces the performance of stereotypic circling behaviour in captive common seals (Phoca vitulina). Anim. Welf. 2001, 10, 53-63.

13. Skibiel, A.L.; Trevino, H.S.; Naugher, K. Comparison of several types of enrichment for captive felids. Zoo Biol. 2007, 26, 371-381. [CrossRef]

14. Howell, S.; Schwandt, M.; Fritz, J.; Roeder, E.; Nelson, C. A stereo music system as environmental enrichment for captive chimpanzees. Lab Anim. 2003, 32, 31-36. [CrossRef]

15. Clark, F.E.; Davies, S.L.; Madigan, A.W.; Warner, A.J.; Kuczaj, S.A. Cognitive enrichment for bottlenose dolphins (Tursiops truncatus): Evaluation of a novel underwater maze device. Zoo Biol. 2013, 32, 608-619. [CrossRef]

16. Clark, F.E.; Smith, L.J. Effect of a cognitive challenge device containing food and non-food rewards on chimpanzee well-being. Am. J. Primatol. 2013, 75, 807-816. [CrossRef]

17. Zhang, Z.; Zhang, D.; Gabaldon, J.; Goodbar, K.; West, N.; Barton, K.; Shorter, K.A. Investigation of Environmentally Dependent Movement of Bottlenose Dolphins (Tursiops truncatus). J. Zool. Bot. Gard. 2021, 2, 335-348. [CrossRef]

18. Brando, S.; Broom, D.M.; Acasuso-Rivero, C.; Clark, F. Optimal marine mammal welfare under human care: Current efforts and future directions. Behav. Process. 2018, 156, 16-36. [CrossRef]

19. Brown, E.F.; Tettamanti, F.; McElligott, A.G. Observing the unwatchable through acceleration logging of animal behavior. Anim. Biotelem. 2013, 1, 20. [CrossRef]

20. Sala, J.E.; Quintana, F.; Wilson, R.P.; Dignani, J.; Lewis, M.N.; Campagna, C. Pitching a new angle on elephant seal dive patterns. Polar Biol. 2011, 34, 1197-1209. [CrossRef]

21. Shepard, E.L.; Wilson, R.P.; Quintana, F.; Laich, A.G.; Liebsch, N.; Albareda, D.A.; Halsey, L.G.; Gleiss, A.; Morgan, D.T.; Myers, A.E.; et al. Identification of animal movement patterns using tri-axial accelerometry. Endanger. Species Res. 2008, 10, 47-60. [CrossRef]

22. Shorter, K.; Shao, Y.; Ojeda, L.; Barton, K.; Rocho-Levine, J.; van der Hoop, J.; Moore, M. A day in the life of a dolphin: Using bio-logging tags for improved animal health and well-being. Mar. Mamm. Sci. 2017, 33, 785-802. [CrossRef]

23. Rutz, C.; Hays, G.C. New frontiers in biologging science. Biol. Lett. 2009, 5, 289-292. [CrossRef] [PubMed]

24. Soltis, J.; King, L.; Vollrath, F.; Douglas-Hamilton, I. Accelerometers and simple algorithms identify activity budgets and body orientation in African elephants Loxodonta africana. Endanger. Species Res. 2016, 19, 311-312. [CrossRef]

25. Holdgate, M.R.; Meehan, C.L.; Hogan, J.N.; Miller, L.J.; Rushen, J.; de Passillé, A.M.; Soltis, J.; Andrews, J.; Shepherdson, D.J Recumbence behavior in zoo elephants: Determination of patterns and frequency of recumbent rest and associated environmental and social factors. PLoS ONE 2016, 11, e0153301. [CrossRef] [PubMed]

26. Razal, C.B.; Bryant, J.; Miller, L.J. Monitoring the behavioral and adrenal activity of giraffe (Giraffa camelopardalis) to assess welfare during seasonal housing changes. Anim. Behav. Cogn. 2017, 4, 154-164. [CrossRef]

27. Rothwell, E.S.; Bercovitch, F.B.; Andrews, J.R.; Anderson, M.J. Estimating daily walking distance of captive African elephants using an accelerometer. Zoo Biol. 2010, 30, 579-591. [CrossRef] [PubMed]

28. Sellers, W.I.; Varley, J.S.; Waters, S.S. Remote monitoring of locomotion using accelerometers: A pilot study. Folia Primatol. 1998, 69, 82-85. [CrossRef]

29. Takahashi, M.; Tobey, J.R.; Pisacane, C.B.; Andrus, C.H. Evaluating the utility of an accelerometer and urinary hormone analysis as indicators of estrus in a Zoo-housed koala (Phascolarctos cinereus). Zoo Biol. 2009, 28, 59-68. [CrossRef] [PubMed]

30. Soltis, J.; Wilson, R.P.; Douglas-Hamilton, I.; Vollrath, F.; King, L.E.; Savage, A. Accelerometers in collars identify behavioral states in captive African elephants Loxodonta africana. Endanger. Species Res. 2012, 18, 255-263. [CrossRef] 
31. Metsios, G.S.; Stavropoulos-Kalinoglou, A.; Veldhuijzen van Zanten, J.J.; Treharne, G.J.; Panoulas, V.F.; Douglas, K.M.; Koutedakis, Y.; Kitas, G.D. Rheumatoid arthritis, cardiovascular disease and physical exercise: A systematic review. Rheumatology 2008, 47, 239-248. [CrossRef]

32. Meagher, R. Is boredom an animal welfare concern? Anim. Welf. 2018, 28, 21-32. [CrossRef]

33. Mason, G.J.; Latham, N. Can't stop, won't stop: Is stereotypy a reliable animal welfare indicator? Anim. Welf. 2004, 13, S57-S69.

34. Fowler, M.E.; Csuti, B.; Sargent, E.L.; Bechert, U.S. An Overview of Foot Conditions in Asian and African Elephants. In The Elephant's Foot: Prevention and Care of Foot Conditions in Captive Asian and African Elephants; Csuti, B., Sargent, E.L., Bechert, U.S., Eds.; Iowa State University Press: Ames, IA, USA, 2001; pp. 3-7.

35. Honda, A.; Sogo, N.; Nagasawa, S.; Shimizu, T.; Umemura, Y. High-impact exercise strengthens bone in osteopenic ovariectomized rats with the same outcome as Sham rats. J. Appl. Physiol. 2003, 95, 1032-1037. [CrossRef]

36. Kuhar, C.W.; Fuller, G.A.; Dennis, P.M. A survey of diabetes prevalence in zoo-housed primates. Zoo Biol. 2013, 32, 63-69. [CrossRef]

37. Lauderdale, L.K.; Shorter, K.A.; Zhang, D.; Gabaldon, J.; Mellen, J.D.; Grainger, D.A.; Walsh, M.T.; Miller, L.J. Bottlenose dolphin habitat and management factors related to activity and distance traveled in zoos and aquariums. PLoS ONE 2021, 16, e0250687. [CrossRef]

38. Zhang, D.; van der Hoop, J.M.; Petrov, V.; Rocho-Levine, J.; Moore, M.J.; Shorter, K.A. Simulated and experimental estimates of hydrodynamic drag from bio-logging tags. Mar. Mamm. Sci. 2020, 36, 136-157. [CrossRef]

39. An Efficient Orientation Filter for Inertial and Inertial/Magnetic Sensor Arrays. Available online: https://forums.parallax.com/ uploads/attachments/41167/106661.pdf (accessed on 12 September 2021).

40. Wilson, R.P.; White, C.R.; Quintana, F.; Halsey, L.G.; Liebsch, N.; Martin, G.R.; Butler, P.J. Moving towards acceleration for estimates of activity-specific metabolic rate in free-living animals: The case of the cormorant. J. Anim. Ecol. 2006, 75, 1081-1090. [CrossRef]

41. Kowalski, J.; Tu, X.M. Modern Applied U-Statistics; John Wiley \& Sons: Hoboken, NJ, USA, 2008.

42. Tang, W.; He, H.; Tu, X.M. Applied Categorical and Count Data Analysis; CRC Press: New York, NY, USA, 2012.

43. Greco, B.J.; Meehan, C.L.; Miller, L.J.; Shepherdson, D.J.; Morfeld, K.A.; Andrews, J.; Baker, A.M.; Carlstead, K.; Mench, J.A. Elephant management in North American zoos: Environmental enrichment, feeding, exercise, and training. PLoS ONE 2016, 11, e0152490. [CrossRef]

44. Lauderdale, L.K.; Walsh, M.T.; Mellen, J.D.; Granger, D.A.; Miller, L.J. Environmental enrichment, training, and habitat characteristics of common bottlenose dolphins (Tursiops truncatus) and Indo-Pacific bottlenose dolphins (Tursiops aduncus). PLoS ONE 2021, 16, e0253688. [CrossRef]

45. Lauderdale, L.K.; Miller, L.J. Efficacy of an interactive apparatus as environmental enrichment for common bottlenose dolphins (Tursiops truncatus). Anim. Welf. 2020, 29, 379-386. [CrossRef]

46. Serres, A.; Delfour, F. Environmental changes and anthropogenic factors modulate social play in captive bottlenose dolphins (Tursiops truncatus). Zoo Biol. 2017, 36, 99-111. [CrossRef]

47. Delfour, F.; Beyer, H. Assessing the effectiveness of environmental enrichment in bottlenose dolphins (Tursiops truncatus). Zoo Biol. 2012, 31, 137-150.

48. Bashaw, M.J.; Bloomsmith, M.A.; Marr, M.J.; Maple, T.L. To hunt or not to hunt? A feeding enrichment experiment with captive large felids. Zoo Biol. 2003, 22, 189-198. [CrossRef]

49. Shepherdson, D.J.; Carlstead, K.; Mellen, J.D.; Seidensticker, J. The influence of food presentation on the behavior of small cats in confined environments. Zoo Biol. 1993, 12, 203-216. [CrossRef]

50. Bassett, L.; Buchanan-Smith, H.M. Effects of predictability on the welfare of captive animals. Appl. Anim. Behav. Sci. 2007, 102, 223-245. [CrossRef]

51. Kuczaj, S.; Lacinak, T.; Fad, O.; Trone, M.; Solangi, M.; Ramos, J. Keeping environmental enrichment enriching. Int. J. Comp. Psychol. 2002, 15, 127-137.

52. Watters, J.V. Toward a predictive theory for environmental enrichment. Zoo Biol. 2009, 28, 608-622. [CrossRef]

53. Watters, J.V.; Miller, J.T.; Sullivan, T.J. Note on optimizing environmental enrichment: A study of fennec fox and zoo guests. Zoo Biol. 2011, 30, 647-654. [CrossRef]

54. Wagman, J.D.; Lukas, K.E.; Dennis, P.M.; Willis, M.A.; Carroscia, J.; Gindlesperger, C.; Schook, M.W. A work-for-food enrichment program increases exploration and decreases stereotypies in four species of bears. Zoo Biol. 2018, 37, 3-15. [CrossRef]

55. Bloomsmith, M.A.; Lambeth, S.P. Effects of predictable versus unpredictable feeding schedules on chimpanzee behavior. Appl. Anim. Behav. Sci. 1995, 44, 65-74. [CrossRef]

56. Krebs, B.L.; Watters, J.V. Simple but temporally unpredictable puzzles are cognitive enrichment. Anim. Behav. Cogn. 2017, 4, 119-134. [CrossRef]

57. Jenny, S.; Schmid, H. Effect of feeding boxes on the behaviour of stereotyping Amur tigers (Panthera tigris altaica) in the Zurich Zoo, Zurich, Switzerland. Zoo Biol. 2002, 21, 573-584. [CrossRef]

58. Johannesson, T.; Ladewig, J. The effect of irregular feeding times on the behaviour and growth of dairy calves. Appl. Anim. Behav. Sci. 2000, 69, 103-111. [CrossRef]

59. Hertel, H. Structure, Form, Movement; Reinhold Publishing, Co.: New York, NY, USA, 1966. 